\section{Changes in Metabolic Enzyme Activities during Thidiazuron-induced Lateral Budbreak of Apple}

\author{
Shiow Y. Wang, Hong J. Jiao, ${ }^{1}$ and Miklos Faust \\ Fruit Laboratory, Agricultural Research Service, U.S. Department of \\ Agriculture, Beltsville, MD 20705
}

Additional index words. glucose-6-phosphate dehydrogenase, glyceraldehyde-3phosphate dehydrogenase, isocitrate dehydrogenase, 6-phosphate gluconate

dehydrogenase, pyruvate kinase

\begin{abstract}
The activity of glucose-6-phosphate dehydrogenase (G6PDH), 6-phosphate gluconate dehydrogenase (6PGDH), isocitrate dehydrogenase (ICDH), pyruvate kinase (PK), and glyceraldehyde-3-phosphate dehydrogenase (GAPDH) were studied in apple (Malus domestics Borkh.) buds during dormancy and thidiazuron-induced budbreak. When buds were dormant, the activity of the glycolytic enzymes GAPDH and PK and the tricarboxylic acid (TCA) cycle enzyme ICDH was low compared to that in nondormant buds. The activity of these enzymes increased during budbreak, peaked when buds were in the green tip stage just before the start of rapid expansion (at 8 days after thidiazuron treatment), and declined thereafter. The activity of pentose-phosphate cycle enzymes G6PDH and 6PGDH was higher in dormant buds than in nondormant buds. 6PGDH was about twice as high as G6PDH. During budbreak and resumption of growth, G6PDH and 6PGDH activity decreased.
\end{abstract}

In deciduous fruit trees, the transition of buds from dormancy to an active state of growth is characterized by rapid metabolic changes (Saure, 1985; Wang and Faust, 1988b). These changes include an increase of promoters (cytokinins) in buds (Pieniazek and Rudnicki, 1971); hydrolysis of starch in wood, upward movement of carbohydrates from bark to buds, and a decrease in carbohydrate content of bark and wood (Hansen and Grauslund, 1978; Priestley, 1981); an increase in nucleic acid, protein, and polyamine content in buds (Barskaya and Oknina, 1959; Wang et al., 1985); an increase in protein hydrolysis and free amino acid content in bark (Titus and Kang, 1982) and in organic acids in buds (Wang et al., 1987); an increase in respiration and ethylene production in buds (Wang and Faust, $1988 \mathrm{~b})$; a reduction of free radical formation (Wang and Faust, 1988b); an increase in the ratio of unsaturated to saturated fatty acids, a decrease in the ratio of free sterols to total phospholipids, and an increase in membrane fluidity (Wang and Faust, 1988a, 1989a, $1989 \mathrm{~b})$. However, little information is available on the changes in activity of the metabolic enzymes in relation to dormancy and thidiazuron-induced budbreak in deciduous fruit trees.

Our previous report (Wang et al., 1986) showed that the plant bioregulant N-phenyl$\mathrm{N}^{\prime}-1,2,3$,-thidiazol-5-ylurea (thidiazuron,

Received for publication 26 Mar. 1990. The cost of publishing this paper was defrayed in part by the payment of page charges. Under postal regulations, this paper therefore must be hereby marked advertisement solely to indicate this fact.

'On leave from the Dept. of Horticulture, Guangxi Agricultural College, Nanning, Guangxi, Peoples Republic of China. break. The enzymes chosen in this study glucose-6-phosphate dehydrogenase (EC
1.1. 1.49; G6PDH), 6-phosphate gluconate dehydrogenase (EC 1.1.1.44; 6PGDH), isocitrate dehydrogenase (EC 1.1.1.42 ICDH), pyruvate kinase (EC 2.7.1.40; PK) and glyceraldehyde-3-phosphate dehydrogenase (EC 1.2.1.12; GAPDH), the key regulatory enzymes in the pentose-phosphate pathway and the glycolytic-TCA cycle.

The growing conditions of 'York Imperial' apple seedlings and treatment methodology used in this study have been described by Wang et al. (1986). The seedlings were planted in 3.5-liter pots and grown in a greenhouse and had not received any chilling. The plants were randomized and 270 seedlings were used for the experiment. Onethird of the plants were used as control, and others were treated with thidiazuron. Thidiazuron $(100 \mu \mathrm{M})$ was prepared in $2.5 \%$ (v/v) dimethyl sulfoxide (DMSO) plus $0.5 \%$ $(\mathrm{v} / \mathrm{v})$ Tween-20 in water and applied to the uppermost five lateral buds with a brush until runoff. Control plants were treated with aqueous DMSO and Tween 20. Radiation sources in the greenhouse consisted of natural daylight and 400-W high pressure sodium lamps (Energy Technics, York, Pa.) that provided a PAR level of $\approx 400$ to 500 $\mu \mathrm{mol} \cdot \mathrm{s}^{-1} \cdot \mathrm{m}^{-2}$ for $12 \mathrm{hr} /$ day (0700 to 1900 $\mathrm{HR})$. Temperatures were $\approx 25 \mathrm{C}$ during the day and 20C at night, and RH was $65 \%$. Control and thidiazuron-treated buds were sampled at 2-day intervals for 12 days. Triplicate bud samples of $0.2 \mathrm{~g}$ fresh weight were collected at each sampling time. Depending on their size, the number of buds required ranged from about eight to 136 . Excised bud tissue was immediately ground in a cold mortar and pestle with chilled extraction medium [a ratio of 1 tissue :1 extraction medium $(\mathrm{w} / \mathrm{v})]$. The extraction medium for each enzyme was: G6PDH-20 mm Tris. $\mathrm{HCl}$ (pH 7.5), 420 mm mannitol, 5 mM KI, 5

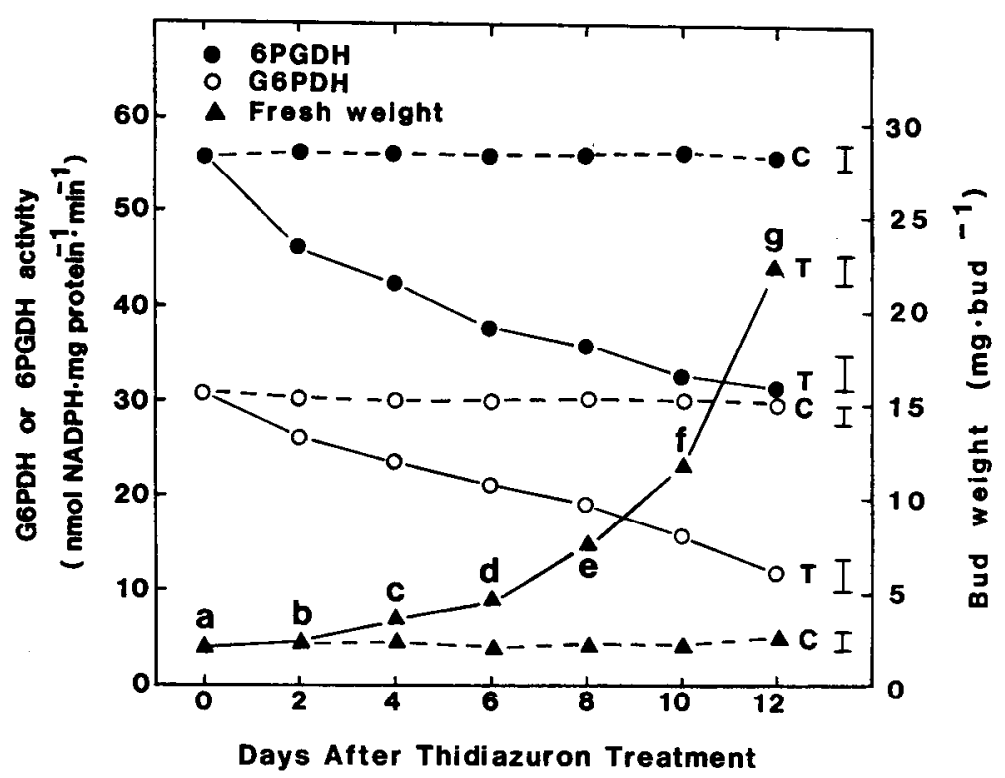

Fig. 1. Changes of fresh weight, glucose-6-phosphate dehydrogenase (G6PDH) and 6-phosphate gluconate dehydrogenase (6PGDH) activity associated with dormancy, thidiazuron-induced (T) budbreak, and growth resumption in apple buds. $\mathrm{C}=$ control. Stages of bud development were classified as follows: a, dormant bud; b, first swell; c, full swell; d, side green; e, green tip; f, bud expansion; $\mathrm{g}$, bud open. Data are the means of three replicate samples. Vertical bars denote LSD at $P=0.05$. 


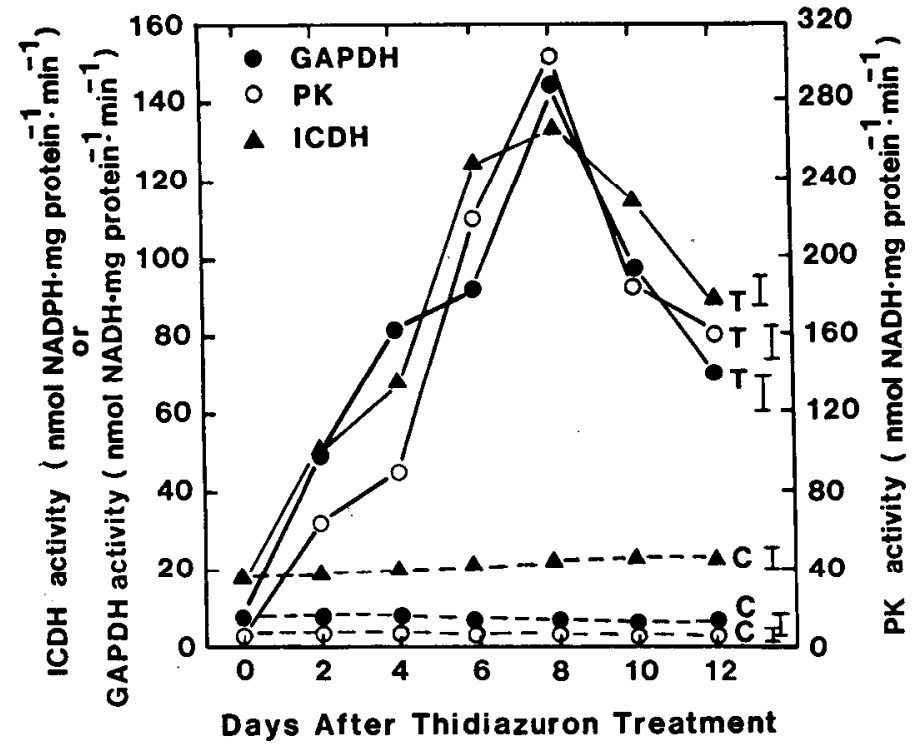

Fig. 2. Changes of glyceraldehyde-3 -phosphate dehydrogenase (GAPDH), isocitrate dehydrogenase (ICDH), and pyruvate kinase (PK) activity associated with dormancy, thidiazuron-induced (T) bud break, and resumption of growth in apple buds. $\mathrm{C}=$ control. Data are the means of three replicate samples. Vertical bars denote LSD at $P=0.05$.

$\mathrm{mm} \mathrm{MgSO}_{4}$, and $1 \mathrm{~mm} 2$-mercaptoethanol; 6PGDH-50 mM Tris buffer ( $\mathrm{pH} 8.0), 7 \mathrm{~mm}$ citric acid, $0.1 \%$ cysteine, 0.1 ' $\%$ sodium ascorbate, $1 \%$ polyethylene glycol (3350), and $1 \mathrm{~mm}$ 2-mercaptoethanol; ICDH and GAPDH-50 mm Tris. $\mathrm{HCl}(\mathrm{pH} 7.2)$ and 6 mu cysteine; PK-50 mm Tris. $\mathrm{HCl}(\mathrm{pH} 7.5)$ and $30 \%$ glycerol. The homogenates were filtered through four layers of Miracloth and centrifuged at $12,000 \mathrm{x}$ g for $30 \mathrm{~min}$ at $0 \mathrm{C}$. The supernatants were used for enzyme assays. All assays were performed in a total volume of $2.0 \mathrm{ml}$. G6PDH, 6PGDH, and ICDH activities were assayed in the following mixture: $50 \mathrm{~mm}$ Tris. $\mathrm{HCl}(\mathrm{pH} 7.6), 5$ $\mathrm{mm} \mathrm{MgCl}_{2}, 0.3 \mathrm{~mm} \mathrm{NADP}^{+}, 3 \mathrm{~mm}$ G6P (or $3 \mathrm{~mm} 6 \mathrm{PG}$ or $2 \mathrm{~mm}$ DL-isocitrate), and 0.1 $\mathrm{ml}$ crude enzyme. GAPDH activity was assayed in a mixture containing $50 \mathrm{~mm}$ Tris $\cdot \mathrm{HCl}$ ( $\mathrm{pH} 8.2), 2 \mathrm{Q} \mathrm{mm}$ sodium arsenate, $1 \mathrm{~mm}$ dithiothreitol, $20 \mathrm{~mm} \mathrm{NaF}, 0.16 \mathrm{~mm}$ ADP, $0.15 \mathrm{~mm}$ GAP, $0.3 \mathrm{~mm} \mathrm{NAD}^{+}$, and $0.2 \mathrm{ml}$ crude enzyme extract. The reaction mixture for PK contained $50 \mathrm{~mm}$ Tris $\cdot \mathrm{HCl}(\mathrm{pH} 7.4)$, $0.16 \mathrm{~mm}$ ADP, $0.1 \mathrm{~mm}$ NADH, $1 \mathrm{~mm}$ phosphoenolpyruvate, $15 \mathrm{~mm} \mathrm{MgCl}_{2}, 50 \mathrm{~mm}$ $\mathrm{K}_{2} \mathrm{SO}_{4}$, four units lactate dehydrogenase, and $0.2 \mathrm{ml}$ enzyme extract. The reaction mixture was incubated at $30 \mathrm{C}$ for $10 \mathrm{~min}$. The enzyme activities were measured for $5 \mathrm{~min}$ as the rate of change in absorbance at $340 \mathrm{~nm}$ using a spectrophotometer (Shimadzu UV160A, Columbia, Md.), and expressed in terms of nanomoles of NADPH per milligram protein per minute for G6PDH, 6PGDH, ICDH and as nanomoles of NADH per milligram protein per minute for GAPDH and PK.

Thidiazuron stimulated budbreak. Two days after thidiazuron application, treated buds began to swell. As previously reported (Wang et al., 1986), untreated buds from the same plant and buds from control plants remained dormant.

The activity of G6PDH, 6PGDH, ICDH,
GAPDH, and PK in apple buds from dormancy to thidiazuron-induced budbreak and bud growth are depicted in Figs. 1 and 2. The control buds remained dormant throughout the experiment and there were no significant changes in the activities of these metabolic pathway enzymes (Figs. 1 and 2). However, the enzyme activity in buds treated with thidiazuron indicated a distinct metabolic shift of glucose-6-phosphate from the pentose-phosphate pathway to the glycolytic-TCA cycle at time of budbreak. G6PDH is the first enzyme of the pentose-phosphate pathway and thus may be a control point in metabolism. Dormant apple buds contained high levels of the pentose-phosphate cycle enzymes G6PDH and 6PGDH. The activation of the pentose-phosphate cycle promotes the supply of several sugars, along with NADPH and other metabolizes, to the cells, which may be necessary for buds to remain dormant. After budbreak, with the commencement of growth, cells resume organization for growth and the activity of two dehydrogenases G6PDH and 6PGDH decreased (Fig. 1).

In contrast, the activity of the glycolysis enzymes GAPDH and PIC and the activity of the isocitrate dehydrogenase (ICDH), a key enzyme in regulation of TCA cycle, increased. Dormant buds have low GAPDH, $\mathrm{PK}$, and ICDH activity. Increased GAPDH, $\mathrm{PK}$, and ICDH activity was associated with budbreak. GAPDH, PK, and ICDH exhibited their maximum activity when the buds were in the green-tip stage just before the start of rapid expansion. The activity of GAPDH, PK, and ICDH declined thereafter (Fig. 2). Substantial changes in the activity of G6PDH, 6PGHD, GAPDH, PK, and ICDH at the time of budbreak indicate that there is a shift in the demand for energy in respiratory pathways and/or for cellular requirements in the buds. The major change in the enzyme activities investigated appears to be completed before the resumption of growth. Thus, the events during the transition period from dormancy to budbreak appear to occur in preparation for the rapid resumption of growth. Sagisaka $(1972,1974)$ also reported a shift of glucose-6-phosphate metabolism from the pentose-phosphate cycle to glycolysis in poplar. twigs in early spring and vice versa in autumn. A metabolic shift was also found in seed germination (Fuerst et al., 1983).

Our data indicate that the changes in glycolytic and pentose-phosphate cycle enzyme activity that occur in thidiazuron-treated apple buds appear to be associated with budbreak and bud growth. The increases and decreases in enzyme activity appear to be characteristic events that are regulated by the overall developmental process, which can be influenced by thidiazuron treatment. Whether the changes in enzyme activity in the thidiazuron-treated buds are similar to the enzyme activity profiles during dormancy and bud growth under natural conditions warrants further study.

\section{Literature Cited}

Barskaya, E.N. and E.Z. Oknina. 1959. The role of nucleic acids in the growth processes and bud dormancy of fruit crops. Soviet Plant Physiol. 6:470-476.

Fuerst, E.P., M.K. Upadhyaya, G.M. Simpson, J.M. Naylor, and S.W. Adkins. 1983. A study of the relationship between seed dormancy and pentose phosphate pathway activity in Avena fatua. Can. J. Bot. 61:667-670.

Hansen, P. and J. Grauslund. 1978. Levels of sorbitol in bleeding sap and in xylem sap in relation to leaf mass and assimilate demand in apple trees. Physiol. Plant 42:129-133.

Pieniazek, J. and R. Rudnicki. 1971. The role of abscisic acid (ABA) in the dormancy of apple buds. Bul. Acad. Pol. Sci., Ser. Sci. Biol. 19:201-204.

Priestley, C.A. 1981. Perennation in woody fruit plants and its relationship to carbohydrate turnover. Ann. Applied Biol. 98:548-552.

Sagisaka, S. 1972. Decrease of glucose-6-phosphate and 6-phosphogluconate dehydrogenase activities in xylem of Populus gelrica on budding. Plant Physiol. 50:750-755.

Sagisaka, S. 1974. Transition of metabolism in living poplar bark from growing to wintering stages and vice versa. Plant Physiol. 54:544 549.

Saure, M.C. 1985. Dormancy release in deciduous fruit trees. Hort. Rev. 7:239-300.

Titus, J.S. and S.M. Kang. 1982. Nitrogen metabolism, translocation, and recycling in apple trees. Hort. Rev. 4:204-246.

Wang, S.Y. and M. Faust. 1988a. Changes of fatty acids and sterols in apple buds during bud break induced by a plant bioregulator, thidiazuron. Physiol. Plant. 72:115-120.

Wang, S.Y. and M. Faust. 1988b. Metabolic activities during dormancy and blooming of deciduous fruit trees. Isr. J. Bot. 37:227-243.

Wang, S.Y. and M. Faust. 1989a. Nitroguanidines induce bud break and change sterol content in apple. J. Plant Growth Reg. 8:143-151.

Wang, S.Y. and M. Faust. 1989b. Changes in membrane polar lipids associated with bud break in apple induced by nitroguanidines. J. Plant Growth Reg. 8:153-161.

Wang, S.Y., M. Faust, and G.L. Steffens. 1985 
Metabolic changes in cherry flower buds associated with breaking of dormancy in early and late blooming cultivars. Physiol. Plant. 65:8994.
Wang, S.Y., G.L. Steffens, and M. Faust. 1986 Breaking bud dormancy in apple with a plant bioregulator, thidiazuron. Photochemistry 25:311-317.
Wang, S.Y., Z.L. Ji, and M. Faust. 1987. Metabolic changes associated with bud break induced by thidiazuron. J. Plant Growth Reg. 6:8595. 